\title{
Discourse structure and relative clause processing
}

\author{
WILLEM M. MaK \\ University of Nijmegen, Nijmegen, The Netherlands \\ and Utrecht University, Utrecht, The Netherlands \\ WIETSKe VONK \\ Max Planck Institute for Psycholinguistics, Nijmegen, The Netherlands \\ and University of Nijmegen, Nijmegen, The Netherlands \\ AND \\ HERBERT SCHRIEFERS \\ University of Nijmegen, Nijmegen, The Netherlands
}

\begin{abstract}
Studies in several languages have shown that subject-relative clauses are easier to process than object-relative clauses. Mak, Vonk, and Schriefers (2006) have proposed the topichood hypothesis to account for the preference for subject-relative clauses. This hypothesis claims that the entity in the relative clause that is most topicworthy will be chosen as the subject. By default, the antecedent of the relative clause will be chosen as the subject of the relative clause, because it is the topic of the relative clause. However, when the noun phrase (NP) in the relative clause is also topicworthy, the preference for the antecedent to be the subject will disappear. This was confirmed in two experiments. In Experiment 1, we tested relative clauses with a personal pronoun in the relative clause. We obtained a preference for object-relative clauses, in line with the assumption that personal pronouns refer to a discourse topic and are thus topicworthy. In Experiment 2, the discourse status of the NP in the relative clause was manipulated; either it was not present in the preceding context, or it was the discourse topic. The experiment showed that when the NP in the relative clause refers to the discourse topic, the difficulty of object-relative clauses is reduced, in comparison with relative clauses with an NP that is new in the discourse, even in the absence of any explicit cue in the relative clause itself. The experiments show that discourse factors guide processing at the sentence level.
\end{abstract}

Sentence processing has most often been studied using isolated sentences. However, normally, sentences are embedded in a meaningful context, and this context may influence processing at the sentence level. In line with this consideration, there is a growing interest in how processing at the sentence level is related to the context in which the sentence is embedded.

Referential ambiguity is one area in which a considerable amount of research has been carried out on the influence of context on sentence processing (e.g., Altmann \& Steedman, 1988; Crain \& Steedman, 1985; Mitchell, Corley, \& Garnham, 1992; van Berkum, Brown, \& Hagoort, 1999). For example, after reading the sentence fragment David told the girl that ... out of context, readers interpret the word that as a complementizer, introducing a complement clause that must be attached to the verb told. When the same fragment is embedded in a context mentioning two girls, there is ambiguity concerning the referent of the noun phrase (NP) the girl. This referential ambiguity induces readers to interpret the word that as a relative pronoun, because they expect a clause modifying the girl, so that the correct referent in the context can be identified (van Berkum et al., 1999).
These findings show that a preference for a certain syntactic analysis at the sentence level can be modulated by the context in which the sentence is embedded. This is due to the fact that sentences in a text form a coherent whole and the interpretation of a sentence depends on the context of that sentence. Often, sentences in a text are coherent because they are about the same referent, the discourse topic. Hoeks, Vonk, and Schriefers (2002) showed that the topic structure of a text influenced processing decisions at the sentence level for coordinations such as those in Sentences 1 and 2:

1. The model embraced the designer and the photographer at the party.

2. The model embraced the designer and the photographer laughed.

Reading such sentences in isolation, readers initially prefer to coordinate the NP the photographer with the NP the designer, so that the two NPs together are the object of the sentence. They perceive the sentences as being about one topic, the model as in Sentence 1, rather than as being about two topics, the model and the photographer, as in 
Sentence 2. This leads to processing difficulty at the verb in Sentence 2. Hoeks et al. showed that when Sentence 2 was preceded by a neutral context, this processing difficulty was indeed present. However, when the sentence was preceded by a context in which, in one of the sentences, the topic consisted of two protagonists, as illustrated in Sentence 3 , the processing difficulty at the disambiguating verb in Sentence 2 disappeared. This finding shows that topichood is an important factor in sentence processing.

3. When they met the fashion designer after the show, the model and the photographer were very enthusiastic.

In the present article, we will investigate how topichood affects the processing of relative clauses in Dutch (see Sentences 4 and 5). Experiments in several languages have consistently shown that object-relative clauses, as in Sentence 5, lead to processing difficulties, as compared with subject-relative clauses, as in Sentence 4.

4. Morgen zal de professor, die de studenten ontmoet heeft, de diploma's uitreiken.

Tomorrow will the professor, that the students met has, the diplomas present.

(Tomorrow the professor, who has met the students, will present the diplomas.)

5. Morgen zal de professor, die de studenten ontmoet hebben, de diploma's uitreiken.

Tomorrow will the professor, that the students met have, the diplomas present.

(Tomorrow the professor, whom the students have met, will present the diplomas.)

The processing difficulty in object-relative clauses has been found in languages with SVO order in the relative clause, such as English (e.g., King \& Just, 1991; King \& Kutas, 1995) and French (e.g., Frauenfelder, Segui, \& Mehler, 1980; Holmes \& O'Regan, 1981), and in languages with SOV order in the relative clause, such as German (e.g., Mecklinger, Schriefers, Steinhauer, \& Friederici, 1995; Schriefers, Friederici, \& Kühn, 1995) and Dutch (e.g., Frazier, 1987; Mak, Vonk, \& Schriefers, 2002).

Note that the difference in word order between the Dutch and the English versions of the relative clauses in Sentences 4 and 5 leads to a difference in the position at which the relative clauses are disambiguated. Due to the strict SVO order in English, English relative clauses are disambiguated at the constituent following the relative pronoun. (In experiments on English relative clauses, the case-ambiguous relative pronoun that was used, instead of the case-marked who/whom.) In Dutch sentences such as 4 and 5, however, only the number marking on the auxiliary disambiguates the relative clauses. Hence, these relative clauses are not syntactically disambiguated before the last word of the relative clause.

Several studies have examined the effect of discourse factors on relative clause processing. Warren and Gibson (2002) investigated the effect of referential processing on sentence complexity. They tested the dependency locality theory (DLT; Gibson, 1998), which proposes that sentence comprehension involves structural integration and structural storage. Crucial to this account is that building a new discourse structure requires more resources than does accessing a previously constructed discourse structure. The cost of integrating two discourse referents in a sentence is dependent on the number of new discourse referents that the integration crosses. For example, in Sentence 6, at the verb attacked, an integration is made between the verb attacked and the senator, which crosses one new discourse referent (attacked), and between the verb attacked and the relative pronoun who, crossing two new discourse referents (attacked and the senator). In sum, this leads to an integration cost of 3. In the corresponding subject-relative clause (7), first, the verb attacked is integrated with the relative pronoun who, crossing one new discourse referent (attacked), and then the NP the senator is integrated with attacked, also crossing one new discourse referent (the senator). In sum, the subject-relative clause has a processing cost of only 2 .

6. The reporter who the senator attacked admitted the error.

7. The reporter who attacked the senator admitted the error.

8. The reporter who you attacked admitted the error.

Warren and Gibson (2002) refined the DLT by proposing that the cost associated with an integration is dependent on the discourse status of the intervening referents. They compared different types of object-relative clauses. In Sentence 8 , the NP the senator has been replaced by the indexical pronoun you. The referents of first- and second-person pronouns are a default part of discourse, even when there is no context. Hence, in Sentence 8, the integration of attacked with who crosses only one new referent, instead of two. In line with their proposal, Warren and Gibson found that the processing cost associated with Sentence 8 was less than the processing cost associated with Sentence 6 .

Kaan (2001) reported an experiment on Dutch in which she contrasted relative clauses that had a full NP in the relative clause with relative clauses that had the pronoun jullie ( $y o u-$ plural, case ambiguous). The data from her experiment also showed that the processing difficulty of object-relative clauses was smaller in the case of a pronoun in the relative clause than in the case of a full NP in the relative clause.

Gordon, Hendrick, and Johnson (2001) also performed experiments in which they studied the influence of the discourse status of the NPs in the relative clause. They used a similarity-based account to explain why the processing difficulty of an object-relative clause is reduced when the subject of the relative clause is a pronoun, as in Sentence 9:

9. The banker that you praised climbed the mountain.

10. The banker that the lawyer praised climbed the mountain.

According to Gordon et al. (2001), the difficulty readers have with object-relative clauses, as in Sentences 9 and 
10 , comes from the fact that these relative clauses require two NPs to be stored in memory and to be subsequently accessed when they are integrated with the verb, whereas in English only one NP has to be stored in the case of subject-relative clauses. The difficulty of accessing the two representations is reduced when they are dissimilar, as in Sentence 9, as compared with when they are similar, as in Sentence 10. Hence, less processing difficulty is found in Sentence 9 than in Sentence 10.

Also, the topichood hypothesis (Mak, 2001; Mak, Vonk, $\&$ Schriefers, 2006) accounts for the processing of relative clauses in terms of the discourse status of the referents. In the present article, the topichood hypothesis will be further explored in two experiments. In the General Discussion section, we will compare the topichood hypothesis with the theories introduced above, in the light of the data from the experiments.

The topichood hypothesis accounts for the preference for subject-relative clauses, as in Sentence 4, over objectrelative clauses, as in Sentence 5, in terms of the topicworthiness of the entities in the relative clause. Although one cannot equate the notion of topic with the grammatical category of subject, there is a strong correlation between the topic and the subject of a sentence (cf. Lambrecht, 1994, p. 131). In most cases, the topic of a sentence is referred to by the syntactic subject. The topichood hypothesis assumes that, other things being equal, the entity that is most topicworthy is chosen as the syntactic subject. To see how this applies to relative clauses, one has to take into account the topicworthiness of the referents of the two NPs, the antecedent of the relative pronoun and the NP in the relative clause. The referent of the antecedent of the relative clause is the topic of the relative clause, because a relative clause always is a statement about the antecedent (cf. Kuno, 1976; Lambrecht, 1988). The NP in the relative clause (henceforth, RC-internal NP), on the other hand, is not topical per se. Therefore, according to the topichood hypothesis, other things being equal, the relative pronoun is chosen as the subject of the relative clause: Its referent is more topicworthy than the referent of the RC-internal NP.

Whether an entity is the sentence or the clause topic is only one of the factors that determine topicworthiness. Other factors that determine the topicworthiness of an entity can either concern properties of the NPs in the sentence, and are thus within-sentence factors, or concern the overall discourse in which the sentence is embedded.

One such within-sentence factor concerns the status of an NP as a full NP or a pronoun. In general, personal pronouns refer to entities that are topical; hence, they are more topicworthy than full NPs. Evidence for the influence of this factor comes from the experiments discussed above in which the RC-internal NP is pronominal (Gordon et al., 2001; Kaan, 2001; Warren \& Gibson, 2002).

Animacy is another within-sentence factor that contributes to the topicworthiness of an entity. Animate entities are more topicworthy than are inanimate entities (cf. van Valin \& Wilkins, 1996). In line with this consideration, several studies have shown that animacy influences relative clause processing (Mak, 2001; Mak et al., 2002,
2006; Traxler, Morris, \& Seely, 2002; Traxler, Williams, Blozis, \& Morris, 2005).

Beyond the sentence level, an entity that is the discourse topic is more topicworthy than is an entity that is not the discourse topic. Hence, the topichood hypothesis predicts that the processing difficulty of object-relative clauses should be reduced when the referent of a full RC-internal NP is the discourse topic, as compared with when it is not.

The theory of Fox and Thompson (1990) is in accordance with the notion that the connection of the relative clause with the discourse context is an important factor. In a corpus study, Fox and Thompson found that nonhuman antecedent NPs that refer to a new entity in the discourse tended to occur with object-relative clauses. The subject of these relative clauses often was a pronoun referring to a discourse topic. In this way, the relative clauses were used to link the new entity to the discourse by explicitly relating it in the relative clause to a discourse topic. Fox and Thompson called this phenomenon grounding. An example is given in Sentence 11:

\section{The car that she borrowed had a low tire.}

Here, although the car is the topic of the relative clause itself, the complex NP as a whole (antecedent NP and relative clause) is linked to the discourse model by means of the personal pronoun she: The entity referred to by the personal pronoun she is the discourse topic.

As has been explained above, the referent of the relative pronoun is the topic of the relative clause. In addition, there may be other topics at other levels, either the sentence level or the discourse level. In that case, there might be competition between the topics at the different levels as to which of them will become the subject of the relative clause. A topic at a different level may be as topicworthy as the referent of the relative pronoun, or it may even be more topicworthy.

According to the topichood hypothesis, it should be possible to manipulate the choice of the syntactic subject in the relative clause by making the entity referred to by the constituent that follows the relative pronoun topicworthy. This should be the case when, for example, the RCinternal NP refers to a topic at a different level than the referent of the relative pronoun, which is the case when it refers to the discourse topic.

Since the topichood hypothesis claims that the NP with the most topicworthy referent is assigned the syntactic function of subject, it thus assumes that it is the difference in topicworthiness between the antecedent of the relative clause and the RC-internal NP that drives the assignment of the subject role.

In the two experiments reported in this article, the topichood hypothesis was further explored. In Experiment 1, we manipulated the topicworthiness of the RC-internal NP by contrasting relative clauses that had a full RCinternal NP with relative clauses that had a pronoun. In the former case, the antecedent of the relative clause was the topic at the clause level, and there were no properties of the RC-internal NP that would render it topicworthy. In the latter case, by contrast, the RC-internal NP was a personal pronoun and, thus, was also topicworthy. Therefore, the antecedent of the relative clause and the RC-internal 
personal pronoun should both be topicworthy and, thus, should compete for the assignment of the syntactic function of subject of the relative clause. In Experiment 2, we varied the topicworthiness of the RC-internal NP by manipulating the context preceding the sentence with the relative clause. Sentences with subject- and object-relative clauses containing a full RC-internal NP were embedded in a discourse context in which the RC-internal NP either was the discourse topic or was not. In the General Discussion section, we will discuss the results in the light of the theories presented in the introduction.

\section{EXPERIMENT 1}

In Experiment 1, a self-paced reading experiment, subject- and object-relative clauses with full NPs were compared with subject- and object-relative clauses with the pronoun jullie (you-plural; see Examples 1-4 in Table 1). The pronoun jullie is case ambiguous, and hence, subjectand object-relative clauses with this pronoun as the RCinternal NP (the ambiguous-Pro/SR and ambiguous-Pro/ OR conditions in Table 1) are disambiguated at the clausefinal auxiliary. Since full NPs in Dutch are case ambiguous as well, relative clauses with a full NP as the RC-internal $\mathrm{NP}$ (the ambiguous-NP/SR and ambiguous-NP/OR conditions in Table 1) are also disambiguated at the auxiliary.

In the ambiguous-NP/SR and ambiguous-NP/OR conditions, both the antecedent and the RC-internal NP are animate full NPs. As was discussed above, previous research with similar sentences (e.g., Mak et al., 2002) has shown longer reading times at the finite verb in objectrelative clauses (ambiguous-NP/OR condition) than in subject-relative clauses (ambiguous-NP/SR condition). According to the topichood hypothesis, this effect is due to the fact that the referent of the relative pronoun is more topicworthy than the referent of the RC-internal NP.

In the ambiguous-Pro/SR and ambiguous-Pro/OR conditions, the RC-internal NP is the second-person plural pronoun jullie ( $y o u$-plural), which is ambiguous between nominative and accusative case. First- and second-person pronouns often refer to entities that are not explicitly mentioned but are present in the situation in which the sentence is heard or read (see also Warren \& Gibson, 2002). This is typically so in conversation, but it also applies to writing: A writer can refer to himself or herself as $I$, and to the reader as you. First- and second-person pronouns are situational pronouns. These pronouns usually refer to the discourse topic. For the ambiguous-Pro/SR and ambiguousPro/OR conditions, the topichood hypothesis predicts that both the referent of the relative pronoun and the referent of the personal pronoun are topicworthy. Thus, reading times at the disambiguating auxiliary in object-relative clauses (ambiguous-Pro/OR condition) should not be longer than the reading times in subject-relative clauses (ambiguousPro/SR condition). It may even be the case that the referent of the personal pronoun is more topicworthy than the referent of the relative pronoun. Reading times in the object-relative clauses should, then, actually be shorter than reading times in the subject-relative clauses.

Most personal pronouns in Dutch are marked for casefor example, the first-person plural pronoun. If there is a case-marked pronoun in the relative clause, the relative clause is disambiguated at the personal pronoun. In Experiment 1 , besides the subject- and object-relative clauses with the case-ambiguous pronoun jullie, we included subjectand object-relative clauses with the case-marked pronouns wij/ons (see Examples 5 and 6 in Table 1; we/us; markedPro/SR and marked-Pro/OR conditions). In these condi-

Table 1

Example Stimuli for Experiment 1

\begin{abstract}
1. Ambiguous-NP/SR: Case-ambiguous full NP in relative clause, subject-relative clause
Ongerust kijkt de hardloper, die de wandelaars in het park gegroet heeft, naar de regenwolken in de lucht.

Worried looks the jogger, who the strollers in the park greeted has, at the rain clouds in the sky.

"The jogger, who has greeted the strollers in the park, looks worried at the rain clouds in the sky."
\end{abstract}

\title{
2. Ambiguous-NP/OR: Case-ambiguous full NP in relative clause, object-relative clause
}

Ongerust kijkt de hardloper, die de wandelaars in het park gegroet hebben, naar de regenwolken in de lucht.

Worried looks the jogger, who the strollers in the park greeted has, at the rain clouds in the sky.

"The jogger, whom the strollers have greeted in the park, looks worried at the rain clouds in the sky."

\section{Ambiguous-Pro/SR: Case-ambiguous pronoun, subject-relative clause}

Ongerust kijkt de hardloper, die jullie in het park gegroet heeft, naar de regenwolken in de lucht. Worried looks the jogger, who you-PL in the park greeted has, at the rain clouds in the sky.

"The jogger, who has greeted you in the park, looks worried at the rain clouds in the sky."

\section{Ambiguous-Pro/OR: Case-ambiguous pronoun, object-relative clause}

Ongerust kijkt de hardloper, die jullie in het park gegroet hebben, naar de regenwolken in de lucht.

Worried looks the jogger, who you-PL in the park greeted have, at the rain clouds in the sky.

"The jogger, whom you have greeted in the park, looks worried at the rain clouds in the sky."

\section{Marked-Pro/SR: Case-marked pronoun, subject-relative clause}

Ongerust kijkt de hardloper, die ons in het park gegroet heeft, naar de regenwolken in de lucht.

Worried looks the jogger, who us-ACC in the park greeted has, at the rain clouds in the sky.

"The jogger, who has greeted us in the park, looks worried at the rain clouds in the sky."

\section{Marked-Pro/OR: Case-marked pronoun, object-relative clause}

Ongerust kijkt de hardloper, die wij in het park gegroet hebben, naar de regenwolken in de lucht.

Worried looks the jogger, who we-NOM in the park greeted have, at the rain clouds in the sky.

"The jogger, whom we have greeted in the park, looks worried at the rain clouds in the sky." 
tions, the relative clauses are disambiguated at the relative pronoun; hence, no difference in processing difficulty should be visible at the auxiliary.

For these sentences with case-marked personal pronouns, the processing difficulty at the point of disambiguation (i.e., at the case-marked pronoun) depends on the relative topicworthiness of the entities in the relative clause. The antecedent of the relative clause is topicworthy since the relative clause is a statement about the antecedent. But the RC-internal NP is a pronoun and, thus, also topicworthy, claiming the function of subject. The case marking on the personal pronoun indicates which of the two protagonists becomes the subject. When the case-marked pronoun is being read, the relative processing difficulty in these two conditions will thus depend on the relative strength of these forces. Either there will be no difference between the two conditions or the accusative pronoun ons (us) in the subject-relative clause should lead to more processing difficulty and, hence, to longer reading times.

\section{Method}

Participants. Sixty students from the University of Nijmegen participated in the experiment. They were native speakers of Dutch and were paid for their participation.

Materials. We constructed 48 sets of sentences. An example of a set of sentences is presented in Table 1 . The ambiguous-NP/SR condition contained a subject-relative clause in which both protagonists were animate full NPs. The ambiguous-NP/OR condition included the object-relative clause counterpart of this sentence. The object-relative clause was derived from the subject-relative clause by changing the number of the auxiliary. In the ambiguous-Pro/SR and ambiguous-Pro/OR conditions the full NP in the relative clause was replaced by the pronoun jullie (you-plural). This pronoun is case ambiguous: Just like the full NPs in the ambiguous-NP/SR and ambiguous-NP/OR conditions, it can be either the subject or the object of the relative clause. In the marked-Pro/SR and markedPro/OR conditions, the pronouns from the ambiguous-Pro/SR and ambiguous-Pro/OR conditions were replaced by the case-marked first-person plural pronouns ons (us-accusative) and wij (wenominative), respectively. The sentence started with a main clause consisting of an adverb or adverbial clause, followed by the tensed verb and the subject of the sentence that was also the antecedent of the following relative clause.

The antecedent of the relative clause was the same across the six conditions. The relative clauses consisted of the sequence die (that) $<$ full/pronominal noun phrase $><$ prepositional phrase $>$ $<$ past participle $><$ auxiliary $>$ and ended with a comma. After the comma, the sentence continued with at least three words.

The layout of the sentences on the screen is given in Sentence 12 (see Table 1, ambiguous-NP/SR condition, for the translation). The first line contained the main clause up to the tensed verb; the second line contained the antecedent, the relative clause, and at least two words of the continuation of the main clause; and the third line contained the remaining words of the sentence. We chose this layout to ensure that the critical region was in the middle of a line on the screen.

\section{Ongerust kijkt}

de hardloper, die de wandelaars in het park gegroet heeft, naar de regenwolken

in de lucht.

Because the case-ambiguous pronoun jullie is plural, we could not vary the number of the NPs across the two types of relative clauses (subject-relative clause vs. object-relative clause): The RC-internal NP always was plural; the antecedent always was singular. As a consequence, the auxiliary in subject-relative clauses always was sin- gular (heeft), and the auxiliary in object-relative clauses always was plural (hebben). Note that the auxiliary in object-relative clauses was thus always one letter longer than the auxiliary in subject-relative clauses. However, any potential effect of this difference would actually work against the predictions of the topichood hypothesis, since in the conditions with case-ambiguous RC-internal NPs the topichood hypothesis predicts that the reading time of hebben will be the same as the reading time of heeft, or even shorter. To prevent the possibility that readers adopt a strategy in which they conclude from the form of the auxiliary whether the sentence is a subject- or an object-relative clause, we included 32 filler sentences, which contained relative clauses with a plural antecedent and a singular RCinternal NP. Sixteen of these were subject-relative clauses, and 16 were object-relative clauses. In these fillers, the antecedent and the $\mathrm{RC}$-internal NP were full NPs. In addition, there were 60 fillers that were part of an unrelated experiment. An example of these fillers is given in Sentence 13:

\section{De gevangene ontsnapte en de bewaker riep meteen zijn} collega's die in de gang op wacht stonden.

The prisoner escaped and the guard immediately called his colleagues who were on guard in the corridor.

The past participles in the relative clause were semantically unbiased with respect to which protagonist was most likely to be the subject of the relative clause. The bias was established in a pretest (see also Mak et al., 2002) in which the participants were shown the nouns paired with the verb, as in Sentence 14:
14. De wandelaars groeten de hardloper.
12345
The strollers greet the jogger.
De hardloper groet de wandelaars.
The jogger greets the strollers.

The items of the present experiment were intermixed with items from other experiments in which verbs were used that were semantically biased to have one of the protagonists as the subject. Twenty participants rated, on a 5-point scale, which of the two situations described was more likely. The items were judged to be not semantically biased if the mean score of the item was between 2.5 and 3.5.

After $25 \%$ of the trials, verification statements were included to ensure that the participants had read the sentences carefully. An example of a verification statement, belonging to the experimental item in Sentence 12, is given in Sentence 15. Care was taken that the statements did not draw the attention of the participants to the experimental manipulation.

\section{De lucht was helder.}

\section{The sky was clear.}

The 48 experimental items and 92 fillers were pseudorandomly divided into two blocks of trials. Six experimental versions were constructed. The items occurred in the same order in each version. Across the experimental versions, each item occurred in each of the six conditions. The participants saw each item only once and saw eight experimental items in each condition. At the beginning of the experiment, there was a practice block of 14 trials. The practice items had constructions similar to the ones used in the experiment.

Procedure. The participants were tested individually. They were seated in a dimly lit room in front of a PC monitor and a panel with three buttons. The course of a trial was as follows. The participants saw a fixation point, indicating where the sentence would begin. By pushing the middle button, they started the trial. The participants then saw the first word of the sentence. The letters of the other words and the commas were replaced by dashes. The full stop at the end of the sentence was visible. When the participants pressed the middle button again, the second word appeared, and the first word was replaced by dashes. This was repeated until the participants had read the whole sentence. In most of the trials, the buttonpress after the last word of the sentence was followed by the fixation point announc- 
ing the next trial. In $25 \%$ of the trials, however, the participants saw the word bewering (statement) for $1 \mathrm{sec}$, followed by a verification statement about the sentence. The participants had to judge whether this statement was consistent with the content of the sentence that they had just read. If it was consistent, they had to press the right button; if not, they had to press the left button.

\section{Results}

Reading times shorter than $50 \mathrm{msec}$ ( 4 cases) and reading times longer than $4,000 \mathrm{msec}$ ( 3 cases) were excluded from further analysis. From the remaining reading times, those that were more than two standard deviations away from the participant and item means at a certain position in each condition (485 cases) were excluded. Following these criteria, $1.4 \%$ of the trials were removed.

Table 2 presents the mean reading times as a function of the type of relative clause and the type of RC-internal NP for the word positions from the determiner of the antecedent up to and including the second word after the auxiliary and for the last word of the sentence.

For all positions presented in Table 2, two ANOVAs were computed, one with participants $\left(F_{1}\right)$ and one with items $\left(F_{2}\right)$ as random variable. Clause type (subjectrelative clause vs. object-relative clause) and NP type (full NP vs. case-ambiguous pronoun vs. case-marked pronoun in the relative clause) were the factors in the analyses. Since, in the conditions with a full NP and in the conditions with a case-ambiguous pronoun, the relative clauses were disambiguated at the auxiliary, the most important prediction at this position concerned an interaction of NP type and clause type in these four conditions. To make sure that a possible interaction was not due to the conditions with case-marked pronouns, at this position and the two following positions, we computed additional ANOVAs, including only the conditions with full NPs and the conditions with case-ambiguous pronouns. Clause type (subject-relative clause vs. object-relative clause) and NP type (full NP vs. case-ambiguous pronoun) were the factors in these additional analyses.

When there was an interaction of NP type and clause type in either the original or the additional analysis, simple main effects for the clause type factor (subject-relative clause vs. object-relative clause) were computed for the different levels of NP type.

In order to increase the power of our statistical tests, we included list as an extra factor in the analysis over participants and item rotation group in the analysis over items (Pollatsek \& Well, 1995).

The sentences started to differ at the RC-internal NP, which was a full NP, a case-ambiguous pronoun, or a case-marked pronoun. At that position and the following position (preposition), only a main effect of NP type was found [at the RC-internal NP, $F_{1}(2,54)=9.56, p<.05$; $F_{2}(2,42)=26.72, p<.001$; at the preposition, $F_{1}(2,54)=$ $\left.29.78, p<.001 ; F_{2}(2,42)=21.08, p<.001\right]$.

At the following position, Determiner 3 , there was a main effect of NP type $\left[F_{1}(2,54)=19.19, p<.001\right.$; $\left.F_{2}(2,42)=22.54, p<.001\right]$ and, more important, an interaction of NP type and clause type $\left[F_{1}(2,54)=4.55\right.$, $\left.p<.05 ; F_{2}(2,42)=4.25, p<.05\right]$. The simple main effects analyses showed that there was no effect of clause type in the conditions with a full NP $\left[F_{1}(1,54)=1.36\right.$, $\left.p>.25 ; F_{2}(1,42)=1.41, p>.10\right]$ and in the conditions with a case-ambiguous pronoun (both $F_{\mathrm{S}}<1$ ). In the conditions with a case-marked pronoun, there was an effect of clause type $\left[F_{1}(1,54)=4.36, p<.05 ; F_{2}(1,42)=4.24\right.$, $p<.05]$. The determiner in the object-relative clause was read $13 \mathrm{msec}$ more quickly than the determiner in the subject-relative clause.

At the following position, Noun 3 , there was again only a main effect of NP type $\left[F_{1}(2,54)=9.86, p<.005\right.$; $\left.F_{2}(2,42)=15.11 p<.001\right]$. At the past participle, there were no main effects or interactions (all $p \mathrm{~s}>.20$ ).

Table 2

Mean Reading Times in Experiment 1 As a Function of Clause Type and Noun Phrase (NP) Type in Relative Clause (With the Words From the Example Sentence from Table 1 in Parentheses)

\begin{tabular}{|c|c|c|c|c|c|c|}
\hline & \multicolumn{2}{|c|}{$\begin{array}{c}\text { Case-Ambiguous } \\
\text { Full NP } \\
\end{array}$} & \multicolumn{2}{|c|}{$\begin{array}{l}\text { Case-Ambiguous } \\
\text { Pronoun }\end{array}$} & \multicolumn{2}{|c|}{$\begin{array}{c}\text { Case-Marked } \\
\text { Pronoun } \\
\end{array}$} \\
\hline & SR & OR & SR & OR & SR & OR \\
\hline \multicolumn{7}{|l|}{ Main clause } \\
\hline Determiner 1 (de) & 294 & 298 & 295 & 299 & 298 & 292 \\
\hline Antecedent noun (hardloper) & 360 & 365 & 353 & 344 & 369 & 337 \\
\hline \multicolumn{7}{|l|}{ Relative clause } \\
\hline Relative pronoun (die) & 325 & 331 & 331 & 343 & 325 & 324 \\
\hline Determiner $2(d e)$ & 269 & 270 & & & & \\
\hline Noun2/pronoun (wandelaars/jullie/ons-wij) & 289 & 293 & 266 & 265 & 263 & 263 \\
\hline Preposition (in) & 290 & 285 & 257 & 265 & 259 & 258 \\
\hline Determiner 3 (het) & 265 & 272 & 253 & 247 & 258 & 245 \\
\hline Noun 3 (park) & 279 & 286 & 261 & 261 & 271 & 263 \\
\hline Past participle (gegroet) & 298 & 294 & 299 & 303 & 304 & 308 \\
\hline Auxiliary (heeft/hebben) & 402 & 430 & 404 & 367 & 365 & 371 \\
\hline \multicolumn{7}{|l|}{ Main clause } \\
\hline Auxiliary + 1 (naar) & 318 & 352 & 328 & 321 & 309 & 308 \\
\hline Auxiliary + $2(d e)$ & 284 & 309 & 296 & 293 & 274 & 287 \\
\hline Last word (lucht) & 389 & 390 & 378 & 385 & 392 & 394 \\
\hline
\end{tabular}

Note-SR, subject-relative clause; OR, object-relative clause; auxiliary $+1,+2$, first and second words after auxiliary, respectively. 
At the auxiliary, an interaction of clause type and NP type was predicted: Reading times should be longer for object-relative clauses than for subject-relative clauses in the conditions with a full NP, whereas in the condition with case-ambiguous pronouns, this effect should not be present or should even be reversed. In the conditions with case-marked pronouns, the relative clauses are already disambiguated at the pronoun; hence, we expected no effect at the auxiliary in these conditions.

At this position, the main effect of NP type was significant $\left[F_{1}(2,54)=9.24, p<.005 ; F_{2}(2,42)=13.89, p<\right.$ $.005]$, and, more important for our predictions, there was indeed a significant interaction of clause type and NP type $\left[F_{1}(2,54)=4.51, p<.05 ; F_{2}(2,42)=5.86, p<.05\right]$. The critical interaction in the four conditions with only caseambiguous RC-internal NPs (full NPs and second-person plural pronouns) was also significant $\left[F_{1}(1,54=10.97\right.$, $\left.p<.005 ; F_{2}(1,42)=16.24, p<.001\right]$.

The simple main effect analyses showed the following pattern. There was no effect of clause type in the conditions with a full NP $\left[F_{1}(1,54)=2.67, p>.05 ; F_{2}(1,42)=\right.$ $1.88, p>.10]$. In the conditions with a case-ambiguous pronoun, reading times were shorter for the object-relative clauses than for the subject-relative clauses [difference, $37 \mathrm{msec} ; F_{1}(1,54)=4.89, p<.05 ; F_{2}(1,42)=4.10, p<$ $.05]$. In the conditions with a case-marked pronoun, in which the relative clauses were disambiguated at the pronoun, no effect of clause type was found (both $F_{\mathrm{S}}<1$ ).

At the first word after the auxiliary, there was a main effect of NP type $\left[F_{1}\left(2,54=9.42, p<.005 ; F_{2}(2,42)=\right.\right.$ $10.98, p<.005]$ and a main effect of clause type in the participant analysis $\left[F_{1}(1,54)=5.69, p<.05 ; F_{2}(1,42)=\right.$ $2.36, p=.13]$. More important, however, the interaction of NP type and clause type was also significant $\left[F_{1}(2,54)=\right.$ $\left.6.47, p<.005 ; F_{2}(2,42)=6.00, p<.01\right]$. In the analysis of the conditions with only case-ambiguous RC-internal NPs (full NPs and second-person plural pronouns), the interaction of NP type and clause type was also significant $\left[F_{1}\left(1,54=9.81, p<.005 ; F_{2}(1,42)=11.66, p<\right.\right.$ $.005]$. The simple main effect analyses showed the following pattern. There was an effect of clause type in the conditions with a full NP $\left[F_{1}(1,54)=18.09, p<.001\right.$; $\left.F_{2}(1,42)=8.21, p<.01\right]$ : Reading times were $34 \mathrm{msec}$ longer for the object-relative clauses than for the subjectrelative clauses. There was no effect of clause type in the conditions with a case-ambiguous pronoun and in the conditions with a case-marked pronoun (all $F \mathrm{~s}<1$ ).

At the second word after the auxiliary, there were main effects of NP type $\left[F_{1}(2,54)=6.53, p<.05 ; F_{2}(2,42)=\right.$ $8.07, p<.01]$ and clause type $\left[F_{1}(1,54)=9.79, p<\right.$ $\left..005 ; F_{2}(1,42)=7.70, p<.01\right]$, and the interaction of NP type and clause type was significant in the item analysis $\left[F_{1}(2,54)=3.85, p=.06 ; F_{2}(2,42)=5.95, p<.05\right]$. Also, in the additional analysis on the conditions with ambiguous RC-internal NPs (full NPs and second-person plural pronouns), the interaction of NP type and clause type was significant $\left[F_{1}(1,54)=5.86, p<.05 ; F_{2}(1,42)=\right.$ $9.31, p<.005]$. The simple main effect analyses showed the following results. In the conditions with a full NP, there was an effect of clause type $\left[F_{1}(1,54)=7.94, p<\right.$ $\left..01 ; F_{2}(1,42)=10.20, p<.005\right]$ : Reading times were $25 \mathrm{msec}$ longer in the object-relative clauses than in the subject-relative clauses. There was no effect of clause type in the conditions with a case-ambiguous pronoun (both $\left.F_{\mathrm{s}}<1\right)$ and in the conditions with a case-marked pronoun $\left[F_{1}(1,54)=2.02, p>.10 ; F_{2}(1,42)=2.65, p>.10\right]$.

At other positions in the sentences, there were no main effects or interactions.

\section{Discussion}

The pattern of results at the verb cluster in the relative clause confirms the predictions of the topichood hypothesis. When there was a full RC-internal NP, reading times were shorter in subject-relative clauses than in objectrelative clauses at the two words following the disambiguating auxiliary. According to the topichood hypothesis, this is due to the fact that the referent of the relative pronoun, which is the topic of the relative clause, is more topicworthy than the full RC-internal NP. When there was a caseambiguous personal pronoun in the relative clause, the reverse was the case: At the auxiliary, reading times were shorter in object-relative clauses than in subject-relative clauses. Note that the reading times in the object-relative clauses were shorter, despite the fact that the auxiliaries were actually one letter longer than the auxiliaries in the subject-relative clauses. The auxiliaries heeft and hebben also differ in frequency (the log frequencies in the CELEX database [Baayen, Piepenbrock, \& Gulikers, 1995] are 11.51 and 10.71 , respectively). Note that the effect cannot be explained by this difference in frequency: Actually, the less frequent auxiliary hebben has shorter reading times than does the more frequent auxiliary heeft. Apparently, processing is difficult when the personal pronoun turns out to be the object of the relative clause. According to the topichood hypothesis, this is due to the topicworthiness of the referent of the personal pronoun: This should make the personal pronoun at least as likely to be the subject of the relative clause as is the relative pronoun. The results show that the readers actually preferred to assign the personal pronoun the subject role. This result is similar to the results obtained by Kaan (2001), who found that the processing difficulty of object-relative clauses was reduced in object-relative clauses with the pronoun jullie. However, she did not find the preference for object-relative clauses that we found in the present experiment. We have no clear account for this difference in results and can only speculate that the difference might be due to subtle differences in the materials used in the present experiment and the experiment by Kaan.

At the RC-internal NP and the positions after it, the reading times were longer in the conditions with a full NP. At the RC-internal NP, this effect was probably due to the difference in length between the conditions. At the following positions, the effect implies greater processing difficulty for the conditions with two full NPs. This difficulty may have been due to the greater similarity of the two NPs in these conditions (cf. Gordon et al., 2001). This may also explain the fact that the effect of clause type occurred later in the conditions with full NPs (at the position after the auxiliary) than in the conditions with the case-ambiguous pronoun jullie. 
The results from the relative clauses with case-marked pronouns can be seen as additional support for the hypothesis that readers prefer to assign the personal pronoun the syntactic function of subject. When the reader encountered the pronoun in the relative clause, it was interpreted as the discourse topic and, therefore, was assigned the subject role. For the object-relative clauses, case marking was compatible with this preference, but for subject-relative clauses, the accusative case marking of the personal pronoun contradicted this preference. Thus, for subject-relative clauses, the reader was forced to adopt a dispreferred analysis of the relative clause on the basis of the case marking on the pronoun, and this led to processing difficulty, as reflected in longer reading times in the conditions with the accusative pronoun (ons) than in the conditions with the nominative pronoun (wij), at the second word after the pronoun.

A potential alternative explanation for this effect is that the pronouns wij and ons differ in frequency. If the pronoun wij is more frequent, this may cause the shorter reading times for the object-relative clauses containing that pronoun. However, this explanation cannot hold, since in the CELEX Dutch database (Baayen et al., 1995), the pronoun ons is actually slightly more frequent than the pronoun wij (the $\log$ frequencies are 10.76 and 10.89 , respectively).

It is also important to note that there was no effect at the verb cluster when there was a case-marked pronoun in the relative clause. Apparently, the case marking was sufficient to resolve the ambiguity for the reader. This is consistent with a finding of Friederici, Steinhauer, Mecklinger, and Meyer (1998), who used case-marked relative pronouns to disambiguate German relative clauses with animate antecedents. In an ERP experiment, they found an effect of clause type at the disambiguating relative pronoun, but no difference at the auxiliary.

\section{EXPERIMENT 2}

In Experiment 1, the form of the RC-internal NP (full NP or pronominal NP) determined the topicworthiness of the NP. The pronouns provided an explicit cue within the relative clause with respect to the topicworthiness of the entity. Hence, one could claim that such an explicit cue is necessary for the factor of topichood to have an influence on sentence processing. If the topicworthiness factor affects relative clause processing independently of whether it is reflected in the form of the RC-internal NP, however, it should affect sentence processing also in the absence of an explicit cue, such as a pronoun. In Experiment 2, we tested this by manipulating the topicworthiness of the RC-internal NPs by means of the context preceding the sentence with the relative clause. In the experiment, subject- and object-relative clauses with an animate full NP as the antecedent and an animate full NP in the relative clause were preceded by two types of context (see Table 3). In the first type of context (neutral context), neither of the protagonists in the relative clause was mentioned. In the second type of context (topic context), the RC-internal NP was the discourse topic. For the relative clauses that were embedded in a neutral context, we expected the same pattern of results as that for sentences in isolation: shorter reading times at the verb cluster of the rela- tive clause in subject-relative clauses than in object-relative clauses. In principle, this effect should occur at the disambiguating auxiliary, but the results of Experiment 1 suggest that the effect may also appear one word downstream, at the past participle. The topichood hypothesis claims that the topicworthiness of the RC-internal NP is higher in the contexts in which the RC-internal NP is the discourse topic than in the conditions with a neutral context. Hence, the processing difficulty of object-relative clauses should be reduced. Even though we compare precisely the same subject- and object-relative clauses as those in the neutral context condition, the topicworthiness of the RC-internal NP will affect the difference between the two conditions: The relative processing difficulty of object-relative clauses should at least be greatly reduced, or may even disappear.

\section{Method}

Participants. Forty students at the University of Nijmegen participated in the experiment. They had not participated in Experiment 1 . They were native speakers of Dutch and were paid for their participation.

Materials and Design. We constructed 36 items. An example of an item is given in Table 3. The first two versions of each item started with a context in which none of the protagonists in the main clause was mentioned (neutral context). The other two versions of the item started with a context in which one of the protagonists in the relative clause was introduced as the discourse topic (topic context). The contexts were then followed by the target sentence, which contained either a subject-relative clause or an object-relative clause with an animate full NP as antecedent and an animate full RC-internal NP. The target sentence was followed by one or two more sentences.

The past participles in the relative clause were semantically unbiased with respect to which protagonist was most likely to be the subject of the relative clause. This was established in a pretest (see Experiment 1). The neutral contexts sketched a situation in which the protagonists in the following target sentence with the relative clause played a natural role. This allowed us to use definite articles for the NPs in the relative clause, even though the referents were not introduced before the relative clause. In the example in Table 3, the neutral context mentions a burglary, which means that the police, the burglar, and the occupants may be expected to appear in the target sentence without further introduction. The naturalness of the use of the definite article for the NP in the relative clause was established in a norming study, in which participants were presented with the texts from the neutral context condition and were asked to choose between the definite and the indefinite articles. In $64 \%$ of the cases, the participants chose the definite article.

Apart from the two protagonists in the relative clause, the target sentence started with a third protagonist, which was the subject of the main clause.

In the topic context conditions, the referent of the RC-internal NP was mentioned in the context, whereas in the neutral conditions, the $\mathrm{RC}$-internal NP was not mentioned before the relative clause. This might induce a difference in the processing of the RC-internal NP between the neutral and the topic conditions. However, this difference was not problematic, since the crucial prediction for the experiment was an interaction: In the neutral context conditions, there should be longer reading times for object-relative clauses than for subject-relative clauses, whereas in the topic context condition, that difference should disappear or even be reversed.

Of the 36 target sentences, 18 had a singular NP as the antecedent of the relative clause and a plural RC-internal NP, and 18 had a plural NP as the antecedent of the relative clause and a singular RC-internal NP.

The relative clause consisted of the sequence die de $<$ noun $>$ $<$ auxiliary $><$ past participle $>$. After the past participle, there was a comma, and after the comma, the sentence continued with either a new clause or a continuation of the main clause. This part of the sentence was the same across all the conditions of an item. 
Table 3

Example Stimuli for Experiment 2

Neutral Context

Topic Context

Intro

Onlangs is er ingebroken in een grote villa in deze wijk. De inbraak heeft veel opschudding veroorzaakt. Ook heeft de zaak veel aandacht gekregen in de media.

"Recently there has been a burglary in a villa in this area. The burglary has caused a lot of excitement. The media have devoted much attention to the case."

\section{Intro}

De inbreker was opgepakt bij een inbraak in een grote villa. Hij wilde enkele dure juwelen stelen uit het pand. Ook wilde hij geld meenemen.

"The burglar has been arrested during a burglary in a large villa. He wanted to steal some expensive jewelry from the house. He also wanted to take some money."

\section{Subject-Relative Clause}

De politie heeft de bewoners, die de inbreker hebben neergeslagen, verteld dat de man nog meer misdaden heeft gepleegd.

The police have the occupants, that the burglar have knocked down, told that the man has committed more crimes.

"The police have told the occupants, who have knocked down the burglar, that the man has committed more crimes."

\section{Object-Relative Clause}

De politie heeft de bewoners, die de inbreker heeft neergeslagen, verteld dat de man nog meer misdaden heeft gepleegd.

The police have the occupants, that the burglar has knocked down, told that the man has committed more crimes.

"The police have told the occupants, whom the burglar has knocked down, that the man has committed more crimes."

\section{Concluding Sentence}

De politie is blij dat de inbreker is opgepakt.

"The police are glad that the burglar has been arrested."

\section{Concluding Sentence}

De politie is blij dat de inbreker is opgepakt.

"The police are glad that the burglar has been arrested."

Note-Word-by-word translations are in given in italics; correct translations are given in italics in quotation marks.

Because word-by-word self-paced reading of a whole text would probably be too annoying for the participants, the texts were not presented word by word, but in segments consisting of one or more words. Noun phrases and prepositional phrases were, in most cases, presented as a whole, but the segments did not contain more than three words. The relative clauses were divided into regions in the way illustrated in Sentence 16:

16. /de inbreker,/die de bewoners/heeft/neergeslagen,/ the burglar,/that the occupants/has/knocked-down,/ (the burglar, who has knocked down the occupants)

The texts were formatted so that the relative clause appeared on a single line, which started with the antecedent and contained at least one segment after the relative clause.

In addition to the 36 experimental items, there were 60 filler items, which were part of an unrelated experiment. The filler items had the same length as the experimental items and included a target sentence that included a coordination that was either a sentence coordination or an NP coordination (see Sentence 13 in the Method section of Experiment 1). The 36 experimental items and 60 fillers were pseudorandomly divided into two blocks of trials. Four experimental versions were constructed. The items occurred in the same order in each version. Across the experimental versions, each item occurred in each of the four conditions. The participants saw each item only once and saw 8 experimental items in each condition. At the beginning of the experiment there was a practice block of four texts. The practice texts were similar to the ones used in the experiment.

Procedure. The procedure was the same as that in Experiment 1, except for the fact that no verification statements were used, because we assumed that the texts (as opposed to isolated sentences) would keep the participants attentive. Also, instead of presenting the texts word by word, multiword regions were used.

\section{Results}

Reading times shorter than $50 \mathrm{msec}$ and reading times longer than 4,000 msec ( 2 cases) were excluded from further analysis. From the remaining reading times, those that were more than two standard deviations away from the participant and item means at a certain position in each condition (68 cases) were excluded. Following these criteria, $0.9 \%$ of the trials were removed.

Table 4 presents the mean reading times as a function of the type of relative clause and the type of context for the segments from the antecedent NP up to and including the second word after the relative clause.

For all the positions presented in Table 4, two ANOVAs were computed, one with participants $\left(F_{1}\right)$ and one with items $\left(F_{2}\right)$ as random variable. Clause type (subject-relative clause vs. object-relative clause) and context (neutral context vs. topic context) were the factors in the analyses. When there was an interaction of context and clause type, simple main effects for the two levels of context were computed, comparing the different clause types (subject-relative clause vs. object-relative clause). In order to increase the power of our statistical tests, we included list as an extra factor in the analysis over participants and item rotation group in the analysis over items (Pollatsek \& Well, 1995).

At the clause-final past participle, there was a significant interaction of context and clause type $\left[F_{1}(1,36)=5.67\right.$, $\left.p<.05 ; F_{2}(1,32)=9.16, p<.01\right]$. The simple main effects analyses showed that after a neutral context, subjectrelative clauses were read more quickly than object-relative clauses [difference, $84 \mathrm{msec} ; F_{1}(1,36)=11.77, p<.005$; $\left.F_{2}(1,32)=18.18, p<.001\right]$, whereas there was no difference between subject-relative clauses and object-relative clauses after topic contexts (both $F \mathbf{s}<1$ ). At this position, there also was a main effect of clause type $\left[F_{1}(1,36)=\right.$ $\left.5.49, p<.05 ; F_{2}(1,32)=8.28, p<.005\right]$.

At the following position, past participle +1 , there was an effect of clause type, although only marginally significant in the participant analysis $\left[F_{1}(1,36)=3.80, p=.06\right.$; $\left.F_{2}(1,32)=4.94, p<.05\right]$. Reading times were longer in the object-relative clauses than in the subject-relative clauses. At this position, there was no interaction of context and clause type. 
There were no main effects or interactions at the other positions.

\section{Discussion}

The results confirm the predictions of the topichood hypothesis: When the relative clauses were preceded by contexts that did not contain the protagonists as discourse topics, the same pattern of results was found as for sentences in isolation. Subject-relative clauses were read more quickly at the verb than at the object-relative clauses. However, when the preceding context contained the referent of the RC-internal NP as the discourse topic, there was no difference in reading times between the verbs of subject- and object-relative clauses. However, the difficulty of the object-relative clauses was not entirely eliminated: At the word cluster after the past participle, object-relative clauses had longer reading times than did subject-relative clauses.

In Experiment 1, the pronouns provided an overt cue with respect to the topicworthiness of the entity. One could hypothesize that such an overt cue is necessary for the topichood to have an influence on sentence processing. However, in Experiment 2, there was no such cue as to the topicworthiness of the NPs involved in the relative clause. The target sentences were identical in both contexts. Hence, the results of Experiment 2 show that topichood also has an immediate effect on relative clause processing when topicworthiness is not signaled by the form of the RC-internal NP.

\section{GENERAL DISCUSSION}

The experiments reported in this article were designed to test the topichood hypothesis (Mak et al., 2006). The topichood hypothesis is inspired by the fact that there is a strong correlation between the topic and the subject of a sentence (cf. Lambrecht, 1994, p. 131). In most cases, the topic of a sentence is referred to by the syntactic subject. For relative clauses, the topichood hypothesis predicts that in the absence of other influences on the choice of the subject, this choice is determined by the relative topicworthiness of the entities in the relative clause. According to the topichood hypothesis, the preference for subject-relative clauses in sentences with animate full NPs should be at-

Table 4

Mean Reading Times (in Milliseconds) in Experiment 2 As a Function of Clause Type and Context (With the Critical Words From the Example Item in Table 3 in Parentheses)

\begin{tabular}{lccccc}
\hline & \multicolumn{2}{c}{$\begin{array}{c}\text { Neutral } \\
\text { Context }\end{array}$} & & \multicolumn{2}{c}{$\begin{array}{c}\text { Topic } \\
\text { Context }\end{array}$} \\
\cline { 2 - 3 } \cline { 6 - 7 } & SR & OR & & SR & OR \\
\hline Antecedent NP (de bewoners) & 615 & 606 & & 627 & 612 \\
RC-internal NP (die de inbreker) & 570 & 549 & & 555 & 569 \\
Auxiliary (hebben/heeft) & 428 & 416 & & 412 & 419 \\
Past participle (neergeslagen $)$ & 517 & 603 & & 530 & 537 \\
Past participle + 1 (verteld) & 494 & 504 & & 485 & 515 \\
Past participle + 2 (dat) & 517 & 535 & & 538 & 552 \\
\hline
\end{tabular}

Note-SR, subject-relative clause; OR, object-relative clause. The region RC-internal NP also includes the relative pronoun. tributed to the fact that the antecedent of a relative clause is the topic of that relative clause and, hence, is preferred as the subject of the relative clause.

Experiment 1 shows that when the RC-internal NP is a full NP - that is, when it is not specifically topicworthythe antecedent is indeed preferred as the subject of the relative clause. However, when the RC-internal NP is a personal pronoun - that is, when it refers to the discourse topic - readers prefer this NP to be the subject of the relative clause. This preference was visible in sentences with the case-ambiguous pronoun jullie (you-plural) in the relative clause. The reading times at the disambiguating auxiliary of the relative clause were shorter when the relative clauses were disambiguated toward an object-relative clause - that is, when the pronoun was the subject of the relative clause.

The conditions with case-marked pronouns provide additional evidence for the topichood hypothesis. If readers prefer a pronoun to be the subject of the relative clause, they should have processing problems when case marking indicates that the pronoun is the object of the relative clause (i.e., in subject-relative clauses), whereas they should have no processing problems when the case marking indicates that the pronoun is the subject of the relative clause (i.e., in object-relative clauses). The results of Experiment 1 support these predictions.

In Experiment 2, the manipulation of topicworthiness was achieved by embedding the same subject- and objectrelative clauses in contexts in which either the entity referred to by the RC-internal NP was the discourse topic or none of the protagonists was a discourse topic. The results show that also in the absence of any overt cue in the relative clause about the topicworthiness of the RC-internal NP, this manipulation affected processing immediately. Objectrelative clauses were more difficult to process at the point of disambiguation than were subject-relative clauses when they were preceded by neutral contexts. If, however, the context introduced the RC-internal NP as the discourse topic, the difference in processing difficulty was not present at the verb cluster, although there was still some residual evidence of processing difficulty at the segment after the relative clause. Note, however, that this residual processing difficulty for object-relative clauses in the topic context condition was much smaller than the processing difficulty for object-relative clauses at the past participle and the following segment in the neutral context condition.

The results of the experiments clearly support the topichood hypothesis. When the RC-internal NP is a personal pronoun, readers prefer this pronoun to be the subject of the relative clause. These effects can be explained in terms of the relative topicworthiness of the entities in the relative clause. The results from Experiment 2 show that topicworthiness also has an effect if it is not signaled by an explicit cue.

In the following, we will discuss the results in the light of the theories discussed in the introduction. According to the DLT (Gibson, 1998; Warren \& Gibson, 2002), the difficulty of the object-relative clauses in our experiments should be reduced when the RC-internal NP has a high discourse status. The results of Experiment 2 can be explained by this aspect of the DLT. When the RC-internal NP is the topic of the discourse, there is no processing cost associated with an in- 
tegration that crosses this NP; hence, the difficulty of objectrelative clauses in the topic context condition is reduced, in comparison with the difficulty of object-relative clauses in the neutral context condition. However, the DLT does not provide an explanation of the fact that object-relative clauses with a pronominal RC-internal NP are actually easier than the corresponding subject-relative clauses.

Gordon et al. (2001) proposed a similarity-based account to explain why the processing difficulty of an object-relative clause is reduced when the subject of this relative clause is a pronoun. The difficulty readers have with object-relative clauses comes from the fact that these relative clauses require two NPs to be stored in memory and to be subsequently accessed, whereas in English this is not the case for subject-relative clauses. The difficulty of accessing the two representations is reduced when they are dissimilar, as compared with when they are similar. This explanation does not hold for Dutch relative clauses, however, because in Dutch the requirement of holding two NPs in memory before they are integrated at the verb would be present for both subject- and object-relative clauses, since both are verb final. Hence, the account by Gordon et al. (2001) does not explain the similar difficulty found in Dutch and other verb-final languages. Conversely, if we apply our account to the Gordon et al. (2001) data, the reduction of processing difficulty for object-relative clauses with pronouns is accounted for by the topichood hypothesis. Because pronouns typically refer to entities that are topical, they are likely candidates for the syntactic function of subject, which reduces (in the case of Gordon et al., 2001) the difficulty of object-relative clauses with a pronominal RC-internal NP, or even makes object-relative clauses with a pronominal RC-internal NP easier than the corresponding subject-relative clauses (as in the present Experiment 1).

The topichood hypothesis is related to MacWhinney's (1977, 1998; MacWhinney \& Pléh, 1988) perspective hypothesis, which claims that the difficulty of object-relative clauses is due to a shift in perspective between the main clause and the relative clause. When the antecedent of the relative clause is the subject (and thus the perspective) of the main clause, there is a perspective shift in objectrelative clauses, but not in subject-relative clauses. This leads to processing difficulty for object-relative clauses, as compared with subject-relative clauses. However, there is a difference between our proposal and the perspective hypothesis. Whereas, in the perspective hypothesis, the preference for subject-relative clauses is based on the fact that the antecedent is the perspective in the preceding main clause, according to our proposal the preference for subject-relative clauses is based on the relative topicworthiness of both entities in the relative clause. The data of Experiment 1 speak against the perspective hypothesis, since a shift in perspective in the object-relative clauses with a pronominal $\mathrm{RC}$-internal NP in fact leads to faster processing.

Thus, the pattern of data shows that topicworthiness, indeed, is a central factor for the processing of relative clauses. Topicworthiness of the entities in the relative clause may also explain the fact that a preference for subject-relative clauses in sentences with full (animate) NPs has been found in languages with different syntactic structures. The processing difficulty has been found not only in languages such as Dutch and German (Mak et al., 2002; Mecklinger et al., 1995; Schriefers, Friederici, \& Kühn, 1995), where the point of disambiguation is at the end of the relative clause, but also in English (King \& Just, 1991; King \& Kutas, 1995), where object-relative clauses are disambiguated at the phrase that follows the relative pronoun. Processing difficulty has also been found in object-relative clauses in French (Frauenfelder et al., 1980; Holmes \& O'Regan, 1981), even though relative clauses in French are not ambiguous: The relative pronoun is different in subject- and object-relative clauses (qui and que, respectively). The preference for subject-relative clauses has also been found in Hungarian (MacWhinney \& Pléh, 1988), in which word order is quite variable. This similarity across languages with clearly different syntactic structures follows straightforwardly from the topichood hypothesis, since the fact that the antecedent is the topic of the relative clause is independent of the syntactic structure of the relative clause.

The picture that emerges from the discussion above is one in which the developing discourse model is very important for processing preferences at the sentence level. The importance of nonsyntactic factors is made particularly clear by the fact that there are many cases in which the syntactic structure of the relative clause does not provide any information about the correct semantic or pragmatic interpretation of that clause. This can be illustrated with an example from a corpus of relative clauses (Mak et al., 2002):

17. Ziege was het die de ongelukkige doelman Boschker de bal tussen de benen door in het net joeg: $3-4$.

Ziege was it who the unfortunate goalkeeper Boschker the ball between the legs through in the net chased: 3-4.

(It was Ziege who chased the ball between the legs of the unfortunate goalkeeper Boschker into the net: $3-4$.)

Sentence 17, from a report of a football match, is syntactically completely ambiguous. Ziege is the one who scores, but this cannot be concluded from the syntactic structure of the sentence. Syntactically, the sentence does not exclude the possibility that Boschker is the subject of the relative clause. That it is, in fact, Ziege who scores can be concluded only from semantic cues, such as the adjective unfortunate in the phrase "the unfortunate goalkeeper Boschker," and from pragmatic knowledge: Since Ziege is a midfield player and Boschker is a goalkeeper, Ziege is more likely to score a goal than is Boschker. Thus, in this sentence, there are no overt syntactic cues to help the reader with the selection of the correct syntactic structure of the sentence. This is not an exception; rather, it is the case in $55 \%$ of the sentences in the corpus of Mak et al. (2002). Thus, in contrast with the situation in English, in which the relative clauses always are disambiguated by word order, in Dutch relative clauses, readers often cannot rely on syntax to arrive at the correct syntactic structure. 
The results from the experiments in this article confirm the predictions of the topichood hypothesis. Processing preferences in relative clauses are, to a large extent, driven by the topicworthiness of the entities in the relative clause. Readers choose the entity that is most topicworthy as the subject of the relative clause. This underlines the importance of discourse factors in sentence processing.

\section{AUTHOR NOTE}

Correspondence should be addressed to W. M. Mak, Faculty of Arts, University of Utrecht, The Netherlands (e-mail: pim.mak@let.uu.nl).

\section{REFERENCES}

Altmann, G., \& Steedman, M. (1988). Interaction with context during human sentence processing. Cognition, 30, 191-238.

BaAyen, R. H., Piepenbrock, R., \& Gulikers, L. (1995). The CELEX lexical database [CD-ROM]. Philadelphia: University of Pennsylvania, Linguistic Data Consortium.

Crain, S., \& Steedman, M. (1985). On not being led up the garden path: The use of context by the psychological syntax processor. In D. R. Dowty, L. Karttunen, \& A. M. Zwicky (Eds.), Natural language parsing: Psychological, computational, and theoretical perspectives (pp. 320-358). Cambridge: Cambridge University Press.

Fox, B. A., \& Thompson, S. A. (1990). A discourse explanation of the grammar of relative clauses in English conversation. Language, 66, 297-316.

Frauenfelder, U., Segui, J., \& Mehler, J. (1980). Monitoring around the relative clause. Journal of Verbal Learning \& Verbal Behavior, 19, 328-337.

Frazier, L. (1987). Syntactic processing: Evidence from Dutch. Natural Language \& Linguistic Theory, 5, 519-559.

Friederici, A. D., Steinhauer, K., Mecklinger, A., \& Meyer, M. (1998). Working memory constraints on syntactic ambiguity resolution as revealed by electrical brain responses. Biological Psychology, 47, 193-221.

Gibson, E. (1998). Linguistic complexity: Locality of syntactic dependencies. Cognition, 68, 1-76.

Gordon, P. C., Hendrick, R., \& Johnson, M. (2001). Memory interference during language processing. Journal of Experimental Psychology: Learning, Memory, \& Cognition, 27, 1411-1423.

Hoeks, J. C. J., Vonk, W., \& Schriefers, H. (2002). Processing coordinated structures in context: The effect of topic-structure on ambiguity resolution. Journal of Memory \& Language, 46, 99-119.

Holmes, V. M., \& O'Regan, J. K. (1981). Eye fixation patterns during the reading of relative-clause sentences. Journal of Verbal Learning \& Verbal Behavior, 20, 417-430.

KAAN, E. (2001). Effects of NP type on the resolution of word-order ambiguities. Journal of Psycholinguistic Research, 30, 529-547.

KING, J. [W.], \& Just, M. A. (1991). Individual differences in syntactic processing: The role of working memory. Journal of Memory \& Language, 30, 580-602.

KING, J. W., \& KuTAS, M. (1995). Who did what and when? Using wordand clause-level ERPs to monitor working memory usage in reading. Journal of Cognitive Neuroscience, 7, 376-395.
KunO, S. (1976). Subject, theme, and the speaker's empathy: A reexamination of relativization phenomena. In C. N. Li (Ed.), Subject and topic (pp. 417-444). New York: Academic Press.

LAmbrecht, K. (1988). There was a farmer had a dog: Syntactic amalgams revisited. In Proceedings of the Fourteenth Annual Meeting of the Berkeley Linguistics Society (pp. 319-339). Berkeley: University of California, Department of Linguistics.

LAMBRECHT, K. (1994). Information structure and sentence form. Cambridge: Cambridge University Press.

MacWhinney, B. (1977). Starting points. Language, 53, 152-168.

MacWhinney, B. (1998). The emergence of language from embodiment. In B. MacWhinney (Ed.), The emergence of language (pp. 213-256). Mahwah, NJ: Erlbaum.

MacWhinney, B., \& PléH, C. (1988). The processing of restrictive relative clauses in Hungarian. Cognition, 29, 95-141.

MaK, W. M. (2001). Processing relative clauses: Effects of pragmatic, semantic, and syntactic variables. Unpublished doctoral dissertation, University of Nijmegen.

MaK, W. M., VonK, W., \& Schriefers, H. (2002). The influence of animacy on relative clause processing. Journal of Memory \& Language, 47, 50-68.

MaK, W. M., Vonk, W., \& Schriefers, H. (2006). Processing relative clauses in Dutch: When rocks crush hikers. Journal of Memory \& Language, 54, 466-490.

Mecklinger, A., Schriefers, H., Steinhauer, K., \& Friederici, A. D. (1995). Processing relative clauses varying on syntactic and semantic dimensions: An analysis with event-related potentials. Memory \& Cognition, 23, 477-494.

Mitchell, D. C., Corley, M. M. B., \& Garnham, A. (1992). Effects of context in human sentence parsing: Evidence against a discoursebased proposal mechanism. Journal of Experimental Psychology: Learning, Memory, \& Cognition, 18, 69-88.

PollatseK, A., \& Well, A. D. (1995). On the use of counterbalanced designs in cognitive research: A suggestion for a better and more powerful analysis. Journal of Experimental Psychology: Learning, Memory, \& Cognition, 21, 785-794.

Schriefers, H., FriedericI, A. D., \& KüHN, K. (1995). The processing of locally ambiguous relative clauses in German. Journal of Memory \& Language, $\mathbf{3 4}, 499-520$.

Traxler, M. J., Morris, R. K., \& Seely, R. E. (2002). Processing subject and object relative clauses: Evidence from eye movements. Journal of Memory \& Language, 47, 69-90.

Traxler, M. J., Williams, R. S., Blozis, S. A., \& Morris, R. K. (2005). Working memory, animacy, and verb class in the processing of relative clauses. Journal of Memory \& Language, 53, 204-224.

van Berkum, J. J. A., Brown, C. M., \& Hagoort, P. (1999). Early referential context effects in sentence processing: Evidence from eventrelated brain potentials. Journal of Memory \& Language, 41, 147-182.

van Valin, R. D., JR., \& Wilkins, D. P. (1996). The case for "effector": Case roles, agents, and agency revisited. In M. Shibatani \& S. A. Thompson (Eds.), Grammatical constructions: Their form and meaning (pp. 289-322). Oxford: Oxford University Press, Clarendon Press.

WARREN, T., \& Gibson, E. (2002). The influence of referential processing on sentence complexity. Cognition, 85, 79-112.

(Manuscript received August 18, 2005; revision accepted for publication May 17, 2007.) 